\title{
Humanity Lost in the Fiction it Created: Problem M, Beginning of Alternative Existence of Alternative Human: Teorem A: A hole in Time: From Purgatory to Apocalypse ${ }^{1}$
}

\section{İmran Gür}

The University of Namık Kemal, Tekirdağ/Turkey Asistant Prof. Dr. Email: iletisim@imrangur.com

Doi:10.5901/mjss.2014.v5n3p533

\section{Abstract}

PROBLEM M, is the endpoint of "single option existence" that imprisons human into the reality he created where humanity is engorged by the reality it created and became enslaved by what it produced; it is the existence itself where fictional reality alternative search produced within "single universe model" absorbs the true reality originated from being, self and the creator. Therefore PROBLEM M is the deadlock about being, knowledge and definition of human that humanity has been unable to resolve since the day of its existence on earth, the deadlock created by the struggle to resolve it via "a single option universe model," and the deadlock reached by the alternative search for resolving this deadlock; and the current human is the problem, the definition of the problem and the diagnosis. Problem M, is the "single option universe model" where communication is the transmission of knowledge, which constricts the existence of mortal human being into "spatial existence". This article is the declaration to humanity of "durational existence" appearing on the realm of being that is alternative human, alternative knowledge, alternative being and alternative existence resolving Problem $M$ with Theorem $A$ and defining human's existence since day one by Problem. M. "Alternative existence" that resolves Problem M with Theorem A, considers the humanity that is a result of Problem $M$ and "a single option universe model" as old; alternative existence of new human as the starting point -0"human history is rewritten". Problem M determines the humanity proposal of alternative existence called Theorem A, history of being and knowledge as "starting point of history," which marks the beginning of the existence of alternative human from 0 to +1 and the olf humanity with Problem M from 0 to -1. This is the creator taking charge of the realm of being, humanity and world agenda.

Keywords: Problem M, Theorem A, beginning of history, apocalypse, beginning of alternative existence, creator interfering in realm of being and humanity

\section{PROBLEM A THEOREM: The Solution of A THEOREM for M PROBLEM²}

\section{PROBLEM M: Great Explosion Universe Model, "Logocentric Universe" "False One Center" "Communicatin is Transmission of Information"}

1.1 M PROBLEM, the Human who Becomes the Slave of What He Produces, from the Mythological Consciousness to Chaotical Consciousness: Spatial Existence

M PROBLEM is the problem of the humanity's solving all the accumulation of the total living, knowing and producing styles about itself, world of entities and the creator with all of the accumulation of knowledge about itself, world of entities and the existence of the creator which can describe itself from the total of these with the "existence with one choice." According to it, the M PROBLEM is a problem of lack of alternative - being confined in one choice- created by its solving the problem of its existing on the earth as a mortal being using its existence qualities and potentials for a "universe model with one choice." (Gür, 2012/1: 101) The humanity which exists in the position of the M PROBLEM itself is both the creator and transposer of the problem. Because of this reason, definition of the M PROBLEM as the problem of not being able to be human and its solution has only been possible by the definition of the alternative existence of the alternative human who is the "alternative of the unrivalled" - the A THEOREM. Because, what makes the humanity M PROBLEM is

\footnotetext{
${ }^{1}$ This article is the declaration to humanity of "temporal existence" appearing on the realm of being that is alternative human, alternative knowledge, alternative being and alternative existence resolving PROBLEM M with THEOREM A and defining human's existence since day one by Problem.

${ }^{2}$ A TEOREMI, M PROBLEMI, It is one of four books written by Imran GÜR and declaration of results.
} 
its being in the "universe model with one choice," it is his not being able to find the alternative because it is the result of what the one choice produces. The alternative existence is the "other choice" which makes the determination and diagnosis of the humanity's having M PROBLEM possible with the humanity in the alternative going out and above the universe model with one choice presenting another human, entity and creator model against the "universe model with one choice." (Gür, 2013/4: 38) The alternative existence consisting of the alternative human, entity and the creator has proved that the humanity who has the M PROBLEM in all of the times of history gathered in the chaotical consciousness of the subject is in the position of the particle that falls into "its own center of gravity around the gravity of the "wrong 1" center in the " (Gür, 2013/2: 47) universe model with one choice" and "disappearing falling into the gravity center of the "wrong 1."Because of this reason, the humanity who has the M PROBLEM in a position of unconscious unification also in the conscious unifications of the structure of consciousness of the age which is the historical process and the result of this process. The unification - the production - has the quality of a structured problem of space, a zero point, blackhole and lack of center not coinciding with the human's potential of existence. The humanity who has the M PROBLEM is a wrong awakening because of the wrong structuring of the "space"s, and the wrong awakening is its problem of mental, bodily and vocal unification, reproduction and productions appearing as a result of its unifying itself with other areas of existence -seen or unseen - because it's not being able to define the problem of falling into the center, getting lost in its consciousness or not being able to define the "thing in itself" existing in itself in the unification. (Gür, 2013/1: 584) The M PROBLEM is the problem of solving - "M" - with the "image consciousness" of the space.

The PLACE is the "universe model with one choice" which is the result and the creator of the present humanity in the M PROBLEM which is the mortal entity standing in the wrong place in the right time - duration - on earth, and the problem of PLACE is the situation which the "historical consciousness" (Gür, 2013/6: 62) becomes unsolvableness because it is solved with the "image consciousness" in the alternative choice's point of view. (Gür, 2012/1: 4) The M PROBLEM has to be solved and the space creating the PLACE - space - problem has to be solved in the ALTERNATIVE. The problem of PLACE in this position is the oldest, the most deep-rooted and the most up-to-date problem that can be solved with the "durational existence" with the existence of the "human in the alternative existence" of the of the new area of existence in which the opportunities of existence which do not exist in the wrong choice. (Gür, 2013/3: 49) The transition of the M PROBLEM into the problem of area is the human's being swallowed by the potential of existence which the "image consciousness" is its own alternative, which cannot be solved in the "universe model with one choice" and which is used wrongly by human. According to it, the PROBLEM OF PLACE which is the result of the human's endeavors to solve the bodily death is finished with the death of the consciousness as well and the humanity did not only be able to solve the bodily death but also it fell into a blackhole - purgatory - in which the consciousness is killed and swallowed by what it established.

\subsection{The Creator, Human and World of Entities Relationship: the "Wrong 1" Center. "communication is transmission of information"}

The M PROBLEM consists of the wrong commentary of the "human, existence and creator" which occurs as a result of basing the humanity's existence upon the wrong universe model with one choice by the chaotic consciousness of the subject that is the representative of the last human gathered around the wrong consciousness. (Gür, 2013/7: 98) Within this context, it takes its existence consisting of material and spiritual knowledge from the unification of the three K's Kant, quantum, chaos - in one point, in the space. Within this context, the M PROBLEM is the problem of wrong unification - closing the space - and it is itself the consciousness, thought and action - architect, engineer and constructor - which creates the problem and which exists in the focus point of the problem, it is the three of them. (Gür, 2013/3: 1687) However, what is ironic is the human's working as only the constructor of the world whose architect and engineer he does not know in the center of the "wrong 1" which the humanity gathers around. (Gür, 2013/56) The M PROBLEM's changing into the problem of place is itself the "tumult" of the "universe with one choice" model which all of the humanity gathers around, no matter East or West, Old World or New World, which is the result of the fiction created by the architect, engineer and the constructor taking the place of the reality.

The M PROBLEM is the area of existence itself in which the human being fills his original area of existence with the others, in which he confines himself in the "historical consciousness" and he lives in the fictionality of the "image consciousness" positioned as the alternative of the "historical consciousness." Fictional consciousness expresses the fictional area in which the human being that cannot become original in the choice of "historical consciousness" destroys its own existence. Wrong unifications cause copying and the copying process causes the human's getting far from its original existence qualities and getting far from them causes him to be driven away from its own original potential of 
existence. (Gür, 2012/3: 659)

Within this context, the M PROBLEM expresses a great process of becoming a wrong image in which all of the historical process continuing from the day the humanity appears in the world of entities to the structure of the last human subject gathers in itself. Thus, the "image consciousness" makes the subject a total of the wrong consciousness which is created by the situation of experiencing the wrong choice again with its structure which the spaces are closed with wrong images in the process of becoming the wrong image - wrong unification - in which all of the historical process unites in the process itself in the structure of the subject who is the human of the age. The "wrong consciousness" is the "wrong 1" center itself. The image of "wrong 1" is the situation which is the end and result of the adventure of worshipping the god whose oldest image is "one eye" in which the humanity became the slave of what he created and could not get out of it. Within this context, the "wrong 1" is the humanity's attempt to suicide, which is the result of the human, creator and the other existence areas mingling, taking the place of each other and this human's leaving his area of existence to other areas of existence. The alternative existence suggested by the THEOREM A is the diagnosis, testimony and announcement of the humanity's gathering around the "wrong 1" and the suggestion of the same perception in the right choice during the process as the process of the suggestion of the original image and the alternative human from the human's own center. Thus, the humanity exists in the time of "nothingness" who does not worship the "real creator" but worships the god it creates and who is swallowed by him. The center of the "wrong 1" is the formation in which the oldest delusion takes the last human into itself, born of the humanity's placing the creator in the position of the total of what he created, adding +1 to 99 which expresses the whole of the world of entities - created universe - and its gathering around the same area of perception. The creator's activity of creating is confused with what is created by human as a result of the confusion of the other areas of existence and the creator's area of existence and their taking each other's place, and the creator transforms into the center of the consciousness of the "wrong 1", a god whose activity of creation unites with the human's creations and who has a share in the human's creations, a god who approves. (Gür, 2013/1: 59) Thus, it is placed into the position of the accomplice who shares the responsibility of the activities done by the creative humanity. (Gür, 2013/5: 54) The center of "wrong 1" is swallowed by the consciousness of the "wrong 1" which is the sacred thing created by the humanity itself and the humanity is in the delusion of thinking its experience is experience with the creator. This is the situation which the real creator of the world of entities and the fictional "wrong 1" change their places in the human consciousness.

\subsection{Thing in itself, consciousness of revelation, reality with 5 dimensions: Durational Existence}

The "consciousness of revelation" which is in the position of the alternative of the "image consciousness" in the alternative existence is the five dimensional reality of the human who is confined in three dimensions in the $\mathrm{M}$ PROBLEM. It is the offer of alternative coming from the creator himself to the "image consciousness" resulting with human's becoming a slave of a fictional god. (Gür, 2012/2: 109) The "consciousness of revelation" is the consciousness of "thing in itself" which the potential in the human being will create an alternative. Alternative human is a "thing in itself" and the "thing in itself" is a structure consisting of "wholeness three in one" +1 . This is the alternative human who consists of "soul LIFE body" and CREATOR unity holding the human in the alternative existence who directly communicates with the creator from "wholeness three in one" in the verticality of its own center. The alternative human is a situation of consciousness which will be able to distinguish the creator from what he created and he is a center of "thing in itself" who does not need the existence of another center because it actualizes its existence with the creator itself. The alternative human is a personal time of existence belonging to itself, he is an original target, a target-human existing in a time of history which exactly coincides with the time of existence of the creator and the world of entities and who exists with this coincidence, who is the reason of the creator to be created, achieved the creator's target of creation. The relationship between the alternative human and the creator expresses the situation which the creator's world of entities - time of existence - actualize both from the inside and outside also as in its 99 and +1 . And the alternative human exists in the position of human who is in the position of "thing in itself" + creator $-3+1$ and on the border of 99 in other words, on the top of the world of entities but who communicates with the +1 and the creation activity of +1 . And the human being who has the PROBLEM $M$ which is the problem of not being able to be human is the human who cannot stand on the border of the 99 because it communicates with the created, swallowed by the other entity circles whom it communicates and because of this reason, it is the human who is not able to be the "thing in itself" center, +1 is the creator who sustains the existence of the entities in the world of entities, protecting the spaces between the entity circles created to be the things they are and according to their aim of creation and he is the creator who does not transform them into each other. Because of this reason vertical transformation between species is not possible. The human's 
becoming horizontal is because of its communication with the substances he is created from and with the created world of entities. The consciousness opened to anyone other than the creator is the consciousness swallowed by the other areas of existence. Who can exist always and everywhere is the creator and the creator's existing always everywhere is not about his doing his creation activity in a certain order filling the "space"s and loading value to the worthless neutriones which are the smallest parts. On the contrary, it is about the +1 's being a specific area of existence because it communicates with what it creates from outside as an off-the-record entity outside the 99+1 model.

Thus, it is about the creator's being off-the-record which can be found both inside and outside the 99+1. Because of this reason, any consciousness who has not met the creator himself cannot stand on the border of the 99 and it cannot save itself from falling into the center and losing his consciousness. Because of this reason, the +1 , which is the activity of making the substance gain volume itself and it exists as the counterpart of the particle sought, will only be possible with the solution of the blackhole. The five dimensional reality with "3"+"1"+1" which can also include its body to the " 3 " +1 " model which is the fifth dimension reality of the creator's activity of creation and the alternative human depends on the right solution of the 99+1 model. The blackhole is in the position of the building stone of the body. Because of this reason it is the excuse of the " $3+1$ " which exists in the position of durational existence to exist in the "historical time." It is the proof that the human can only achieve the five dimensional reality not getting rid of his body but making his body immortal. The actualization of this situation is the form or aim of creation of the human in the beginning itself. Thus, the first human is the human who exists as "wholeness three in one" a "thing in itself" and he directly communicated with the creator. The human who is confined in the "spatial existence" and who has the M PROBLEM could not find this coherence again. All of the situations other than the "experience of revelation" are artificial because the communication of the human who cannot find the "thing in itself" with the creator is impossible. The subject who loses its quality of being human is lost in the gravity of a false center and he is swallowed by this center because the experience of the subject consists of this falseness' being copied and idealized.

\section{TEOREM A: Great Claim Universe Model: "Quality in Absence, Freedom in Existence" "True One" "Alternative Means Different ONE"}

\subsection{Unrivalled Creator:}

It is the creative free will who created the world of entities and who continues to create it and who created the alternative of the world of entities and who has no alternative because of this reason. Its being free will is the principle of "equality in nonexistence, freedom in existence." Nonexistence is the zero point. Here, both the creator and the world of the created are equal. The creator has no alternatives since no entity other then the unrivalled creator cannot pass the world of entities from zero to +1 and it will never be able to do it. Universe - entity is a confrontation of a great free will. The unique creator who presented its free will making the existence from nonexistence and who can demolish it when it wishes has created the alternative of the unrivalled opening the "existence to free will."While the existing world of entities is a "model of universe with one choice" with all of its elements - THE M PROBLEM- the choice of the alternative of the unrivalled is the great claim of the unrivalled creator who also created the other universe model -alternative existencethat is the "alternative of the unrivalled" as the ability of the human's choosing the alternative with the principle of "freedom in existence." The unrivalled creator who completed 99 of the world of entities to +1 , in other words who make it pass from zero to +1 - who loaded value to neutrons - has become a circle of existence included to the 100 but seperate from it - both recorded and unrecorded - and it becomes the creator who exists in the alternative choice as the circle of existence which communicates with what it has created from outside at $100+1$. This circle of existence of the creator is its existence is in the other choice which the human being that exists in the "one choice" universe model cannot be together with it without passing to the alternative one. This circle of existence of the creator is its existence in the other choice which the human being who exists in the "one choice" universe model cannot be with him without passing to the alternative universe. The +1 of the creator in the $100+1$ model expresses the situation of his being the creator of the alternative universe in which he is completely independent from what he created in another world of entities, like the 5-dimensional reality of the alternative human being can only be possible with its passing to the alternative universe. (Gür, 2013/7: 112)

\subsection{Alternative of the Unrivalled, the Alternative Human Being:}

The human being is the "great claim" of the unrivalled creator. It is created as the "free will" for the unrivalled creator to 
reach the "alternative of the unrivalled" choice for its finding the "other choice" in the world of entities. The entity who meets the creator in the alternative of the unrivalled is the entity who met the creator in the "freedom in existence" principle as created in the world of entities, in other in the creation itself. The human being who is the alternative of the unrivalled is not the alternative of the creator, it is the entity who was created as "thing in itself" that does not have the problem- alternative other than itself. Because of this reason, "thing in itself" is the human's being an entity who can be the alternative of the unrivalled not having an alternative other than himself as unique and thing in itself, which can only occur in the practicing the action of creation together with the creator, creating with him. This situation is the presence of the "unrivalled human" in the other choice in which he is "freedom in existence", which distinguishes him among other human beings and which makes him one and unique as it makes the human superior to the other entity circles and different from them as an entity. Thus, the human who is the "alternative of the unrivalled" is the human who achieved his intention for being created and who made it true. The alternative human who unites with the unrivalled in the alternative of the unrivalled is the human whose pulse of life goes together with the pulse of the creator, "whose pulse goes on together with the pulse of the creator" for it meets the creator in creating with the "body LIFE spirit" coherence in the $3+1$ model which is "thin in itself." Because of this reason this human is the human who met the creator who is +1 in the action of creating with the quality of being human at the border of 99 . This is the exact human who is not the unrivalled creator and who directly communicates with the creator who went above the other entity circles. It took its life from the one who gives and takes life. Because of this reason its life can only be given by the creator who created him. This is the end of the mortal human who makes the M problem a problem of place and the form of immortality in which the life of the alternative human who is the alternative of the unrivalled. It is above all of the world of entities which exist under 99 for it exists in 99 and it communicates with +1 .

\subsection{Blackhole:}

Blackhole is the center of creation itself in which the time and place and form collapse and the matter changes from the unseen to seen, from seen to unseen. It is the universe of creation itself in which the world of entities cannot be completed in the absence of +1 which is impossible to be diffused and in which the balance of the universe will collapse when it increases. Thus, it is the center itself which the humanity that loses its form - being human- goes into it quickly. Because of this reason, the area in which the form of the body will collapse and the body will gain form again - death and resurrection - is the blackhole itself. The intervention of the creator who is $100+1$ and who is not included in the +1 , who gives form to the matter which gains form with the continuous creating fo the creator 99', which keeps its form - time and place balance - which cannot be recorded, it is the blackholes' swallowing the world of entities in other words doomsday itself. What will spoil the present balance of the universe is the intervention of the creator who has his own area of existence - alternative universe -outside the created universe that is none of what he created, to the world of entities from outside. According to it, the creator is the creator who creates the world of entities continuously, who is in the world of entities with the potential of +1 or out of the world of entities with its existence which is $100+1$, who can be both recorded and unrecorded. The humanity will experience death and resurrection in other words giving the matter form again when it enters into the blackhole - doomsday- . Giving the matter form happens in the same way in the present world of entities. Blackhole is the building stone of the body. It is the area of all humanity's death and - deformation - and resurrection - and reformation.

\subsection{Duration:}

The present world of entities which the 99+1 model is a completeness consisting of the total time both lived and not lived for the history of existence and the history of humanity. The time is duration and the duration is the total energy potential which makes the world of entities continue. The action of creation of the creator which is the +1 of the 99 is his giving opportunity to use the duration given to himself. The duration is 100 thousand years which the "blackholes" which are the areas of the creation activity of the creator and where the present, the past and the future come together in the present also become included in the present situation. The fifty thousand years of this duration belong to the past and fifty thousand years of it belong to the alternative choice which the human does not use. The situation which is known as parallel or baby universes is the other being included in the duration used -past - of the other fifty thousand years which is recorded in the world of entities. The duration used means the situation of the human beginning from the first moment he starts to live spiritually and bodily on earth to his present situation and it expresses the potential of the humanity which it practices in one choice, as its M problem. The forty thousand years of this fifty years duration is the duration in which 
the human existed on earth as a spiritual being together with unseen creatures (neutrinoes). And the ten thousand years is the time in which the human gained body - value adding to the neutriones - and he existed in the world of entities, in other words it is the time in which he is created with the claim of "being an exact human." The body is the indispensable element of the human being. What distinguishes him among the unseen entities and makes him superior is his bodily form, unlike the usual thoughts -"the condition of being one and unique, having form in that shape, the fingerprint." The other unused fifty thousand years time is the other choice which the human did not choose, it his time collected in the past against himself- not increasing or decreasing - during the past time he lived with his aim he could not put into practice. Now, it is the collection and the explosion that will be created by the future in which one of the two choices created the blackhole and the past collections which the other collected as the alternative existence. In other words, the alternative fifty thousand years time which is not used during the M PROBLEM time - paralel universe - will explode the used past to the M PROBLEM. According to it, now, the humanity's enlarging and exploding the blackhole which is the future created by the humanity in the choice of M PROBLEM as a collection meaning humanity's adding a fifty thousand more to the past fifty thousand because of its being "awakening of the past of fifty thousand years, total unit of its being experienced again" because of the "wrong 1" which the humanity gathers around - it is the doomsday process. As it will be understood, the fifty thousand of the present come from the blackhole - future gathered in the wrong choice - in other words the humanity is going to the future it creates. The alternative human's living in the world of entities will create a great repelling power which will repel the "wrong 1" to its own center in which the unused potential fifty thousand will explode the other choice. It is its permitting the continuation of this cycle with the principle of "freedom in existence" - the intervention is made from the outside, the alternative universe - as the creator +1 . The human being uses this permission for 100 years from his time of existence. The creator does not increase or decrease as the "free will" both from inside and outside. This situation explains the blackhole formation. The blackhole is itself the area which starts to open in the world of entities, with his bodily death - star whose energy ended - because the human's not schoosing the alternative in the ten thousand years of the fifty thousand years time in which the human creates its nonexistence. The blackhole is the building stone of the body, thus it is the future which it already chooses for itself because of wrong potential. The future is collected by the humanity because of its choice in the present, in other words the past will be swallowed by the fifty thousand - blackhole.

\subsection{Neutrinoes: Unseen Creatures:}

The alternative human's being "thing in itself" which has "body LIFE spirit" integrity is an "integrity three in one" which bceomes real which he loads value to neutrinoes which are the area of "angels, jinnees, devil and human spirit"that is not recorded because they do not gain value although they are the unseen existence area of the creator who is +1 both outside and inside and they are included in the total duration. This way, human is the entity that lives together with the unseen creatures until he gains body in this area of existence. To be human is to be taken from this area of existence and to gain body. However, the death of the human who continues his life in the M PROBLEM with his lonely body and his potential of -LIFE- in the total time is to continue living as neutrione that did not gain value without increase or decrease - but as an addition to the black hole - in the total time while living since its spirit is not in itself. In this sense mental unifications beceome true by the unseen existence areas which the human spirit communicates. The "wrong I" center which the human gathers around as mental unification is here. The experience takes place with the unseen areas of existence, not with the creator. Because the spirit is not in the human. This situation explains why the present humanity is M PROBLEM from the first day to the present day as M PROBLEM. The "space" areas which are the centers of the human's search and productions about himself is the situation of human which means he is captured because of his spiritual area communicationg with these areas of existence. The reason why the human existence stayed at the upper border of the M PROBLEM is the human's communicating with the unseen areas of existence - because he cannot unify his body and his spirit - and this communication's being perceived as the communication with the creator. The human's own reality which he thinks he finds is all of the experiences - visions - in this area. Today, the "wrong 1" center in which the humanity is swallowed is the loss of consciousness forming with these areas of existence. Humanity is captured by his spiritual area communicationg with the unseen creatures and by the one who use it. (Gür, 2013/9: 46) It is the why the humanity experiences the past again and why the M PROBLEM takes the humanity to the past inversion. Because the unseen areas of existence are only collection, intellect and collected memory, unlike the human. Creating the present is a privilege only belonging to human. The human lost this privilege communicating the unseen creatures - because he could not find the creature and the alternative. Human's spirit and body being able to unite is possible only with its taking the LIFE potential from the creator - linking the pulse to its pulse - the creator's uniting the 
spirit with the body and the body with the spirit like in the continuous activity of creation and getting rid of the communication with other areas of existence. It means the consciousness of "thing in itself"s being able to be in connection with the creator and seperate it from all areas of exsitence existing in the verticality of the "thing in itself". (Gür, 2013/8: 42) The verticality is the fifth dimension reality and it means communication with the creator in $100+1$. This situation is the "zero point of history" in which the human, the alternative of the unrivalled communicates with the unrivalled creator and the alternative duration of existence starts at the esence of the existence and at its time of history.

\section{The End of the Spatial Existence, Beginning of the Durational Existence from Purgatory to Doomsday}

The beginning of the durational exsitence is the creation of humanity who has M PROBLEM "a new, great center of repelling" - center of repelling - against the present humanity. (Gür, 2013/9: 43) The old human's counting from zero to 1 backwards is the human's going to the doomsday, to the blackhole, who is in the purgatory, in the nothingness. The human's passing from zero to +1 is the A THEOREM's eliminating the M PROBLEM and the new five dimensional human's starting to live in the area of existence. This situation means the present humanity's process of passing from purgatory to doomsday. Potentials of existence in the A THEOREM exist against the alternative human - it is of the present humanity who has M PROBLEM - old human - against who is "a thing in itself" in the exactly autonomous "wholeness three in one", who consists of the $+1(" 3 "+1 "=4)$ which the thing in itself communicates directly. The alternative "ONE" center is a great center of repelling which will expand to the outside pulling the humanity existing in the gravity area of the wrong "1" center to its own center. The repelling force is the situation of its actualizing itself pushing the human without a center who gathered around the "wrong 1" - humanity fallen into the purgatory, to the nothingness - and its passing to the "durational existence" as a "wholeness three in one" which solves the PLACE problem for the benefit of the alternative existence - THE ALTERNATIVE HUMAN'S AREA OF EXISTENCE. This is the situation of its completion. Its exact counterblance for the humanity is the immortal human's, that is to say the alternative humans's starting to live in the world of entities. On the other hand, it expresses the end of the exsitence for the mortal humanity who has M PROBLEM. (Gür, 2013/10: 57) According to it, the "doomsday" is the opening of the paralel universe existing in the alternative's area of existence position to the human. The alternative universe opened is the unification of the spirit and the body of the human who could not actualize his alternative and his meeting the unseen areas of existence which the humanity communicates. The creator's activity of creation is to load value to neutrinoes like in the alternative human. The blackhole is the loading of +1 value to the spirit of the human whose body mixes with the other areas of existence with the soil but whose spirit exists in the area of existence as neutriones, in other words, it is the process of his being created again. This process is the sudden meeting of the human who cannot pass to the fifth dimension as $3+1$ with the fifth dimension, in other words it is his perceiving his real form in the blackhole. This situation expresses the 100+1 situation, in other words it expresses the $100+1$ situation of the creator's intervention to the world of entities with the appearance of the alternative human. The zero point of the history in which the alternative existence starts and the alternative human appears means the time which the intervention of the creator that is the unrivalled "ONE" to the world of entities starts. The INTERVENTION of the CREATOR to the world of entities, to the humanity has started NOW. The intervention of the creator means the offer of ALTERNATIVE doomsday and the warning of END to the humanity who goes to its own doomsday. (Gür, 2013/11: 64) Because, the one hundred thousand years time - past, future and present - has accumulated in the PRESENT.

\section{References}

Gür, (2012/1) İmran, The Daily of İmage (İmgenin Günlüğü) Alternative Existence: Spatial Existence, The Criticism of Durational Existence, Publisher: Cinius, İstanbul, July-2012, 256p.

Gür, Imran, (2012/2) "The End Of The Postmodern Subject The New Human Alternative Existence, The Consciousness of Revalation, Sense it Self, God Particle", Itobiad, Journal of the Human and Social Science Researches, 2012 | Cilt.1, Sayl: 4 - Volume.1, Issue: 4, p.98-131

Gür, İmran, (2012/3), "Copy, Bionizm, Falce Center, Searcing In New Life" The Journal of Academic Social Science Studies (JASSS) Volume 51: İssue:8, December, p. 657-692.

Gür, Imran, (2013/1) "The Relationship of Detective Narration, Fiction, Subject And The New Name Of Detective: Postmodern Mystery", Humanitas, International Journal of Social Scienties, Number:1, January 2013, p.45-60

Gür, Imran, (2013/2), "The Postmodern Subject In the Process of Taransformation From the Current Existence to the Alternative Existence: Image Consciousness", Modern Turkısh Literatüre ResearchesYeni, Year:5, Volume.9, january-June, p.33-56.

Gür, Imran, (2013/3) "The Space Problem In The Poem of Tuğrul Tanyol: The God of The Subject, Sound-Existence: Thing It Itself, God Particle", The Journal of Academic Social Science StudiesInternational Journal of Social Science Volume 6 Issue 2, February, p. 
565-592,

Gür, İmran, (2013/4) "The Principles Is Postmodern Subject", The Journal of New İdea", Volume: 5; İssue:11, p.45-62

Gür, İmran, (2013/5), "Experience of The Absolute, Great Consciousness, Constructed Consciousness, Art of Consciousness In My Red", Turkish Studies - International Periodical For The Languages, Literature and History of Turkish or Turkic Volume 8/1 Winter 2013, p.1571-1598

Gür, İmran, (2013/6), "The, Volition Ethics As The Alternative of The Matchless: The Voluntary Human As The Own Purpose Of Creation", The Journal of History School Volume: 7/XVI, 2013, p.34-56

Gür, İmran, (2013/7), "The Other Personality Problem Of The Subject, The Notion Of Crime And Abetment According To Aslı Erdoğan" TSA / Year: 17 Volume: 4, December-2013, s. 47-68

Gür, İmran (2013/8), "Kâtip Çelebi -As Example of Interrelation Between Consciousness Have Been Destructed and As Example Of Inquiry Consciousness", , The Journal of Oriental Studies, Volume: 11, 2013/1, p.56-72

Gür, İmran, (2013/9), "An Indigenous Offer Of The Turcs For The Time's Area Problem And The Description Of The Area Of TheAlternative Assets In The Ibrahim Prophetess And The DeliDumrul Stories", International Journal of New İdea, Volume:5, Issue, 10, p. 87-111

Gür, (2013/10), "The Alternative of The Matchless, Existence of New Human, The Zero Point of History", The Journal of Kurgan Literatüre, Year: 8, Volume: 14, July- August 2013, p. 40-45

Gür, İmran, (2013/11), "M PROBLEM: The "Wrong 1 Center" Of The Centerless Subject, As A Mistake Of Arcitecture, Engineering And Construction Founded By Humanity, The Dream Of Humanity Changing Into Nightmare: Tree Time" Humanitas, , International Journal of Social Scienties, Number 2, December, 2013, p.48-64 